\title{
Optimeret 3D-modellering - nye muligheder for databaseintegrering
}

\section{Af geolog Peter Scharling, GEUS}

Igennem mange år har GEUS stået for indsamling og vedligeholdelse af den nationale boringsdatabase, Jupiter, der i dag indeholder over 240.000 boringer. Denne er nu suppleret med den nationale geofysiske database, Gerda, der indeholder borehulslogs, overfladegeofysisk samt i nær fremtid også seismik.

Traditionelt har man anvendt data fra databaserne ved at lave et udtræk af de ønskede data for derefter at importere dem til relevante visualiserings-, analyse- og tolknings-
Tankegangen bag EarthFX's produkter, hvor fundamentet til et succesfuldt projekt bliver skabt i den indledende fase med datahåndteringen. (Grafik: Forfatteren modificeret efter EarthFX)

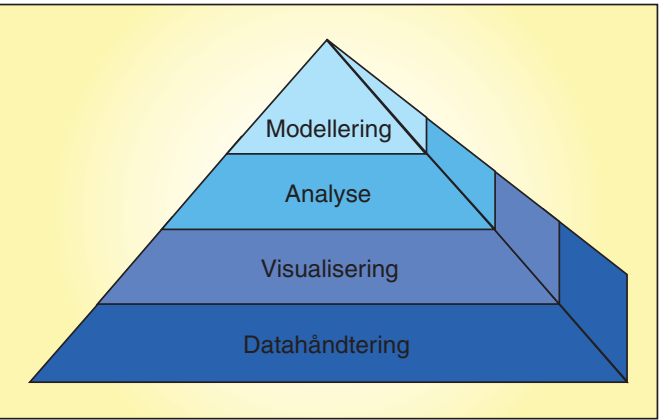

værktøjer. Denne metode har ét altoverskyggende problem, der specielt kommer til udtryk i forbindelse med opdateringer af modeller. De nationale databaser opdateres løbende og vil derfor altid indeholde de nyeste tilgængelige data. Dette er ikke tilfældet for geologiske, geokemiske eller grundvandsmodeller, der baserer deres datagrundlag på dumps fra databaserne. Modellerne forældes og har med mellemrum

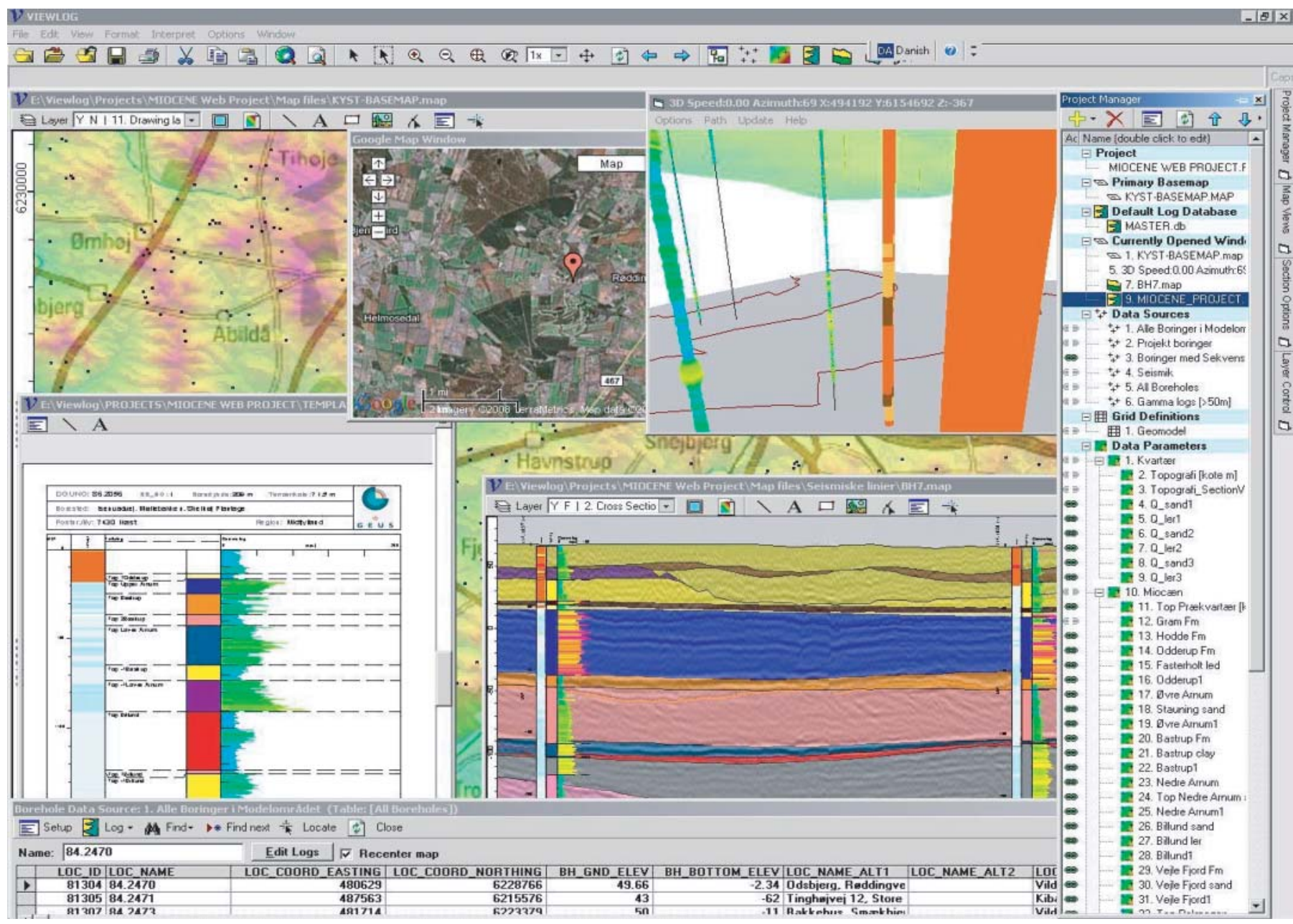

Viewlog var oprindeligt et avanceret log-tolkningsvcerktøj. I dag er Viewlog udviklet til et komplekst geologisk modelleringsvcerktøj, der formår at integrere alle relevante data. Viewlog arbejder ud over det avancerede logmodul også med fladekort såsom GIS-temaer og griddede flader, langs tvcersnit, i 3D, kobling til google maps samt direkte adgang til data i databaserne. (Grafik: Forfatteren) 
brug for at blive opdateret på baggrund af de nyeste data. Processen med at konvertere de rå database-dumps til anvendelige input i modellerne i forbindelse med opdateringer er ofte så kompliceret, at det næsten er lige så nemt at lave en hel ny model.

\section{Baggrunden}

Denne artikel tager udgangspunkt i en del af et ph.d.-projekt, der har til formål at undersøge de miocæne akviferer i Midtjylland. Siden 1998 har der været indsamlet seismiske data samt geofysiske logs til bestemmelse af udbredelsen af de Miocæne akviferer. Data er tolket i en sekvensstratigrafisk forståelsesmodel for området. Det har resulteret i en række rapporter af Erik Skovbjerg, GEUS, der tilsammen giver en god konceptuel forståelse for både de dannelsesmiljøer, der igennem Miocæn var styrende for de sedimentære aflejringer, og den rumlige udbredelse. For at kunne bruge denne viden til en egentlig beregning af akvifér-volumener og sammenhænge samt en forbedret forståelse for grundvandets udbredelse og bevægelse i en senere grundvandsmodel er det dog nødvendigt med en 3D-model.

Det har været afgørende for valget af software, at modellen bliver fremtidssikret, således at den nemt kan opdateres, når nye data kommer til. Der har også været lagt vægt på, at det valgte program formår at håndtere meget store datamængder, da det ofte er en begrænsende faktor ved storskalamodellering. Endelig skulle der efterfølgende være nem adgang til modellen, både hvad angår datagrundlaget og den færdige model samt den videre præsentation af den færdige model for den brede offentlighed.

\section{Software}

Valget af software faldt på Viewlog, der er udviklet af det canadiske firma EarthFX (www.earthfx.com). Viewlog arbejder på 4 overordnede planer, hvor hvert plan skaber grundlag for at kunne optimere arbejdet på det næste plan.

Det nederste niveau, Data Håndtering, er til at begynde med det mest tidskrævende, men det skaber grundlag for, at det videre arbejde bliver succesfuldt. Data læses direkte fra databaserne og bliver derved ikke importeret og konverteret, før de kan anvendes. Data bliver derimod filtreret og manipuleret gennem forespørgsler, der aktiveres, når data bliver anvendt i projektet. Det gør, at alle projekter, der bygger på data fra databaser, bliver opdateret sammen med databaserne - og import af ASCII-filer er fortid!

Niveau 2, Visualisering, skaber grundlaget for forståelsen af sammenhænge mellem forskellige datatyper og derved også den efterfølgende analyse. Derfor er det altafgørende, at der er et bredt spektrum af muligheder for at visualisere og kombinere forskellige data. Kortvisualiseringen er inddelt i 3 overordnede grupper.

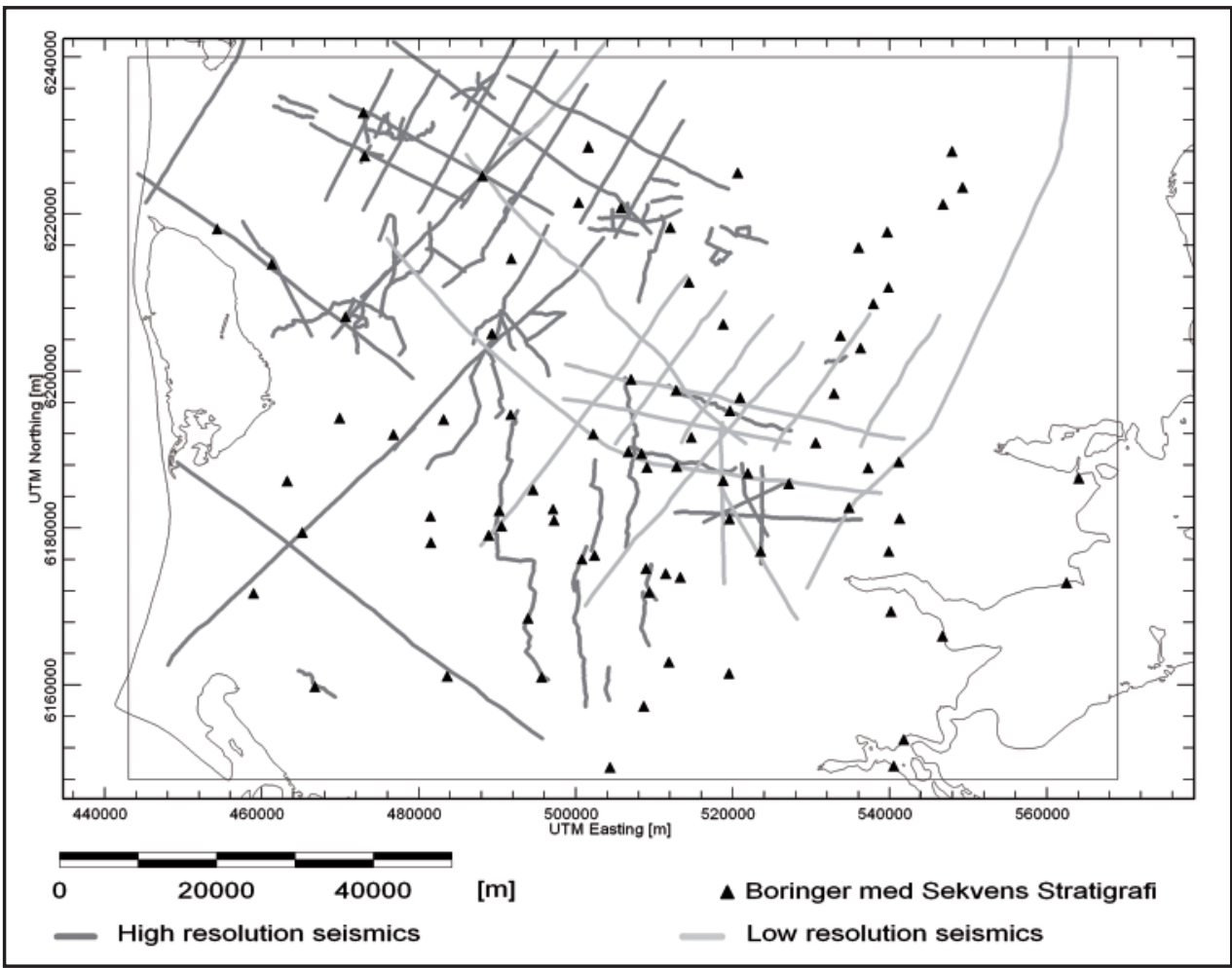

Oversigtskort over modelområdet samt tilgcengelige data med sekvensstratigrafisk information. (Grafik: Forfatteren)

a. Tegningsobjekter og GIS-generede data som shape-filer, der let linkes til eller importeres ind i Viewlog, og som kan bruges til at

visualisere veje, byer, vandløb o.l. Projekter, der arbejder med data i UTM-koordinater, kan kombineres med et google-map-visuali-
Viewlog er oprindeligt udviklet som et avanceret logvisualiserings-og analyseringsvcerktøj. Data bliver hentet direkte fra databasen, og det er muligt at kombinere alle typer logs og geologi sammen med egne tolkninger i samme rapport. (Grafik: Forfatteren) 
seringsmodul, der yderligere forbedrer forståelsen af projektområdet (Shape-filer kan bestå af enten polygoner, linier eller punkter med tilhørende koordinater; derudover kan der også være ekstra oplysninger tilknyttet de enkelte punkter, linier eller polygoner).

b. Griddede data som en digital højdemodel, geologiske flader eller grundvandsspejlet.

c. En del af Viewlogs fundament er en meget avanceret logdatabase, der muliggør sammenstilling af alle forskellige datatyper i samme logvisning. Eksempler kan være lithologi, geokemi, geofysik eller filter-sætninger.

Disse data kan visualiseres som fladekort i 3D, langs tværsnit eller som "Fence diagrammer”. Logdata kan visualiseres som selvstændige logs eller integreret med de andre data.

Niveau 3, Analyse, dækker for dette projekt i høj grad tolkning af sekvensstratigrafiske flader, da målet er en rummelig sekvensstratigrafisk model. Fladerne er tolket direkte i boringer, langs tværsnit eller som højdekurver på fladekort.

Den endelige Modellering er for dette projekt interpolationen af de tolkede flader, så de tilsammen danner den rummelige sekvensstratigrafiske model.

\section{Modelområdet}

Modelområdet dækker et areal på omkring $10.000 \mathrm{~km}^{2}$. Til at tolke sekvensstratigrafien er der brugt omkring 80 boringer, hvoraf mange indeholder gammalogs samt omkring 100 seismiske profiler svarende til mere end $1.000 \mathrm{~km}$ seismik. Til at understøtte den sekvensstratigrafiske tolkning over store afstande er palynofacies-analyser, der indi-

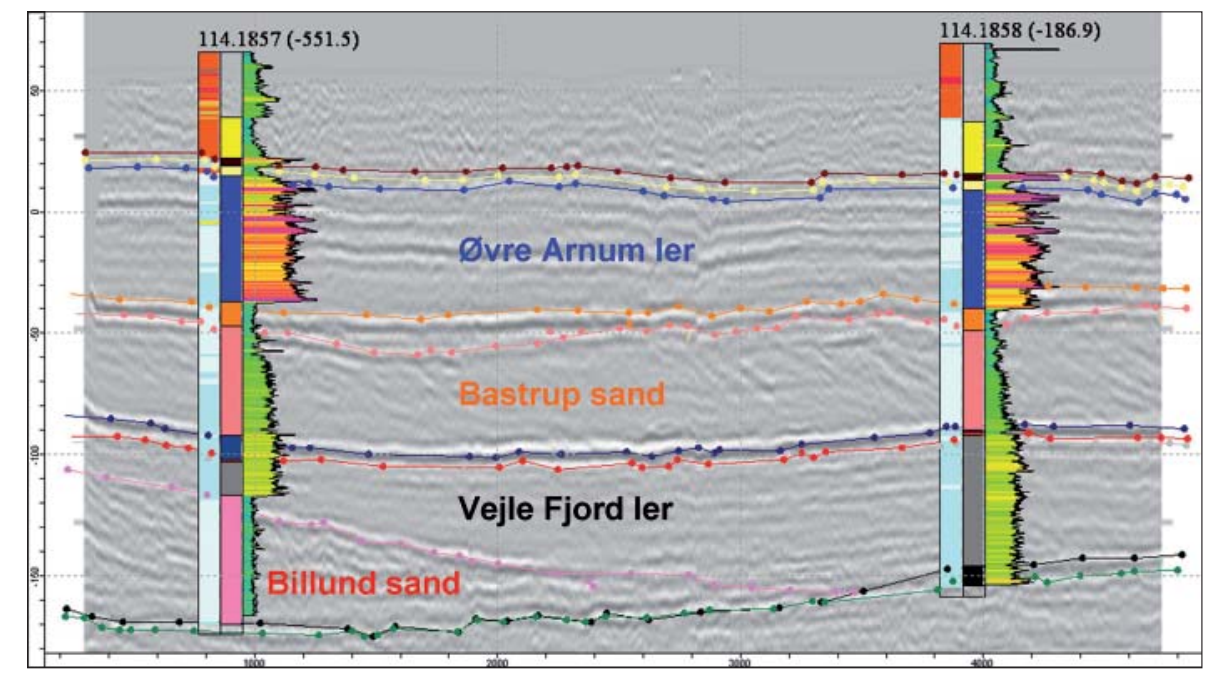

Tolkning af stratigrafiske flader langs et seismisk profil. Boringer teet ved profilet er også vist. Boringerne viser tv. en lithologisk log fra Jupiter, i midten en stratigrafisk tolkning, th. en gammalog fra Gerda. (Grafik: Forfatteren)

kerer sedimenternes alder, fra omkring 40 boringer medtaget. Derudover er relevante boringer fra Jupiter taget med i betragtning undervejs i tolkningsforløbet.

Viewlog henter data direkte fra de to nationale databaser, Jupiter og Gerda. I dette tilfælde bliver databaserne opdateret lokalt på den pågældende arbejdscomputer, men det ville også have været en mulighed at arbejde på en central server, hvor databaserne bliver opdateret automatisk. I Viewlog sammenstilles de lithologiske logs fra Jupiter med gamma logs fra Gerda, og DGU-nummeret bruges til at kæde de to datatyper sammen ved logvisningen. Til at tolke boringerne oprettes en speciel tabel i projektdatabasen. I denne tabel lagres de tolkede stratigrafiske horisonter sammen med en reference til den

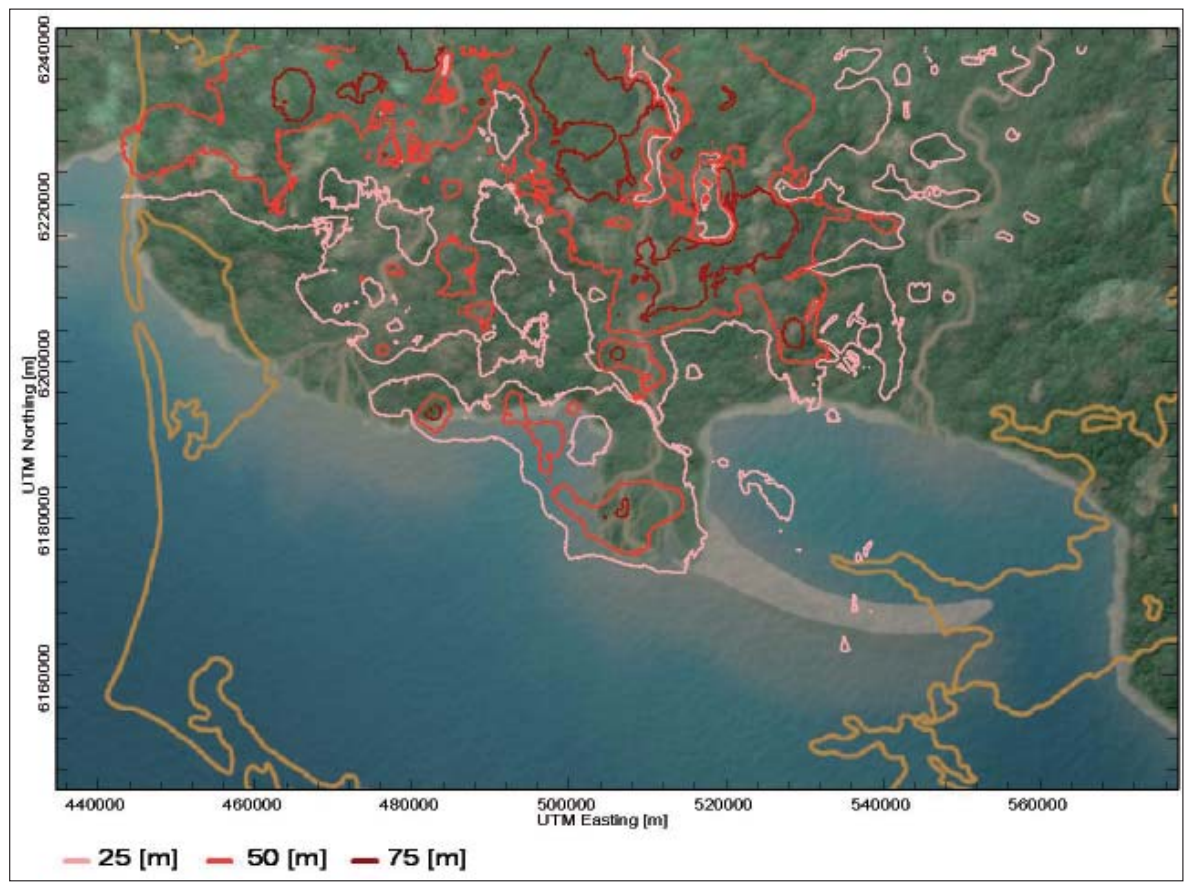

Modellerede sandtykkelser aflejret for ca. 22 mio. år siden kombineret med et samtidigt palceogeografisk kort fra Rasmussen, E.S. 2006: Kortlcegning af Grundvandsmagasiner i Vejle Amt 2004. GEUS rapport 2006/12. (Grafik: Forfatteren) tolkede boring. Denne tolkning foregår inde fra Viewlog og det er ligeledes muligt at vise den lithologiske, geofysiske og tolkede log i samme log-opsætning.

Langs hvert eneste seismiske profil er der lavet et tværsnit, hvor de stratigrafiske horisonter er tolket på baggrund af reflektorerne. I de tilfælde, hvor boringer med eller uden gamma logs befinder sig i umiddelbar nærhed at de seismiske profiler, er de vist på tværsnittet for at støtte tolkningen. Horisonterne er tolket som punkter, der er forbundet til en sammenhængende linie. Interpolation af horisonterne foregår som en iterativ proces, hvor det ofte er nødvendigt at tilføje støttepunkter i områder med svag datadækning for at tvinge horisonterne til at følge den konceptuelle model. Det er dog meget vigtigt at separere støttepunkterne fra tolkninger baseret på fysiske data i tolkningspunktet, da støttepunkterne ofte skal justeres, når der kommer nye data til

Den endelige model består i dette tilfælde af 22 flader, der tilsammen udgør den rummelige model. Nogle af fladerne repræsenterer regionale sekvensstratigrafiske horisonter, som kan forventes at være til stede overalt inden for modelområdet, mens andre flader er brugt til at underinddele de sekvensstratigrafiske lagpakker i de tilfælde, hvor der lokalt er markante lithologiske variationer.

Med denne type model har man markant forbedret muligheden for at udføre rumlige estimatberegninger, som sandtykkelser for enkelte akviferer eller tykkelser for dæklag af ler over akvifererne. Når den rummelige model er skabt, giver den også yderlige input til dårligt forståede områder af geologien, da man kan generere et vilkårligt tværsnit inden for modelområdet. Geologiske strukturer, der før kun var beskrevet i konceptuelle modeller, træder nu tydeligt frem og kan ofte bidrage til en forbedret forståelse for det geologiske dannelsesmiljø. I dette tilfælde er Brande Truget et godt 
eksempel på en regional, geologisk struktur, der har haft enorm betydning for aflejringen af store akviferer i et bælte ned igennem Midtjylland, og som ligeledes træder tydeligt frem på tværsnit og i 3D.

\section{Fra tolkning til rapport}

Opsætningen af figurer til rapporter er en integreret del af Viewlog, og det fungerer ved, at man skifter mellem en arbejdsplatform, hvor der arbejdes i rigtige koordinater (UTM i dette tilfælde) og en rapportplatform, hvor den ønskede opsætning og udsnittet fra arbejdsplatformen bliver vist sammen med figurtekst, logo, indramning m.m. Det betyder også, at rapportfigurerne bliver opdateret i det øjeblik, projektet opdateres med fx nye data i databasen.

Til at udbrede det endelige projekt til interessenter og offentligheden generelt har EarthFX udviklet et Web Server-modul, hvor offentligheden kan logge ind og se dele af projektet, selv lave tværsnit i den rummelige model eller udforske de anvendte boringer. Det er i selve Viewlog muligt at skifte til rapportformat og printe fladekort, tværsnit og boringer med loginformation ud. Projektet er opsat på følgende Web Servermodul og kan frit inspiceres på adressen:

http://www.earthfx.com/EARTHFX/denmark/

Fra indgangssiden skal der klikkes direkte på “MAPS” i øverste venstre hjørne.
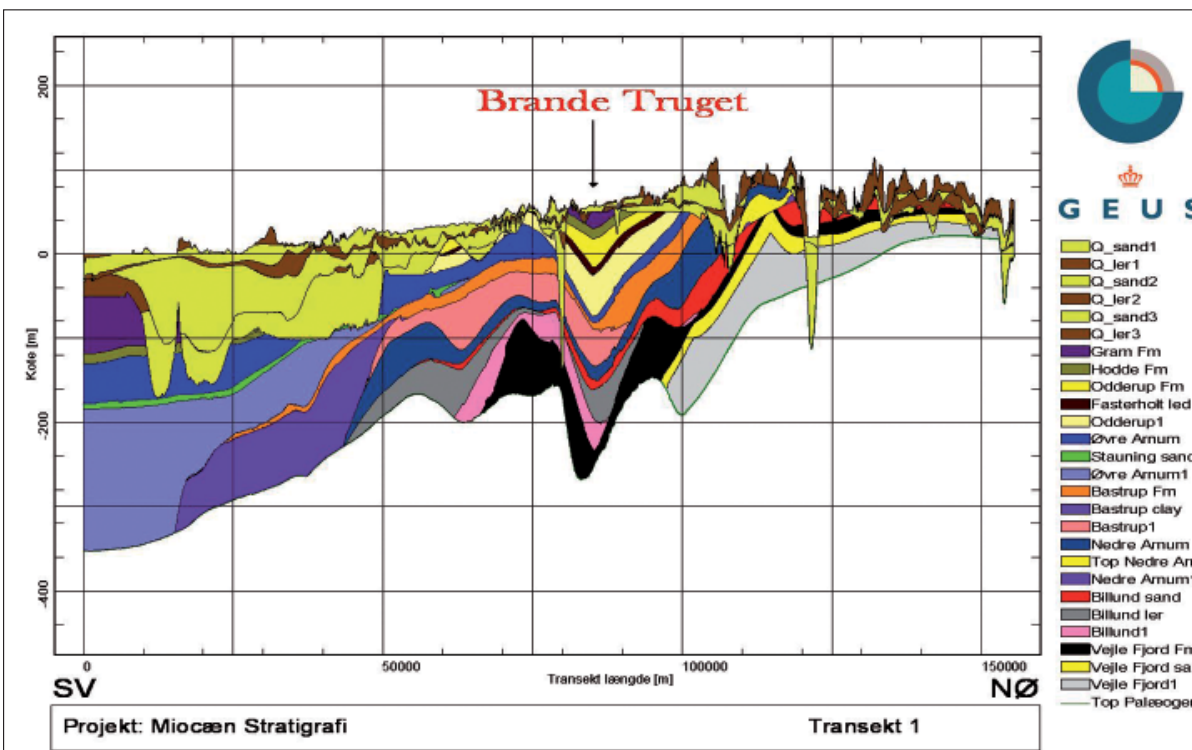

ํำ G E U S

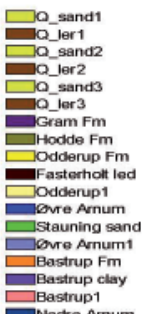
Dedre Anum Nodre Arnum1 Billund sand Veille Fiord Fm Veile Flord Fm
Veile Fiord san

NØ-SV-gående tværsnit gennem Midtjylland. De store sandmcegtigheder aflejret i Brande Truget ses tydeligt.(Grafik: Forfatteren)

Nye muligheder for udnyttelse af data Et af de store problemer hidtil har været manglende software til håndtering af de store mængder data samt fraværet af en samlende platform, der formår at integrere de mange forskellige typer geodata under et. Dette projekt har demonstreret, at Viewlog formår at sidde direkte oven på de meget store nationale databaser og stadig fungere effektivt.
Ud over håndteringen af de store databaser består Viewlog-projektet også af et stort antal shape-filer, omkring 100 tværsnit og mere end 200 grids på hver over 1 mio. celler. Ved anvendelse af Viewlog til datahåndtering, visualisering, analysering og modellering åbnes der således for helt nye muligheder for udnyttelse af vores allerede tilgængelige data fra de nationale geodatabaser.

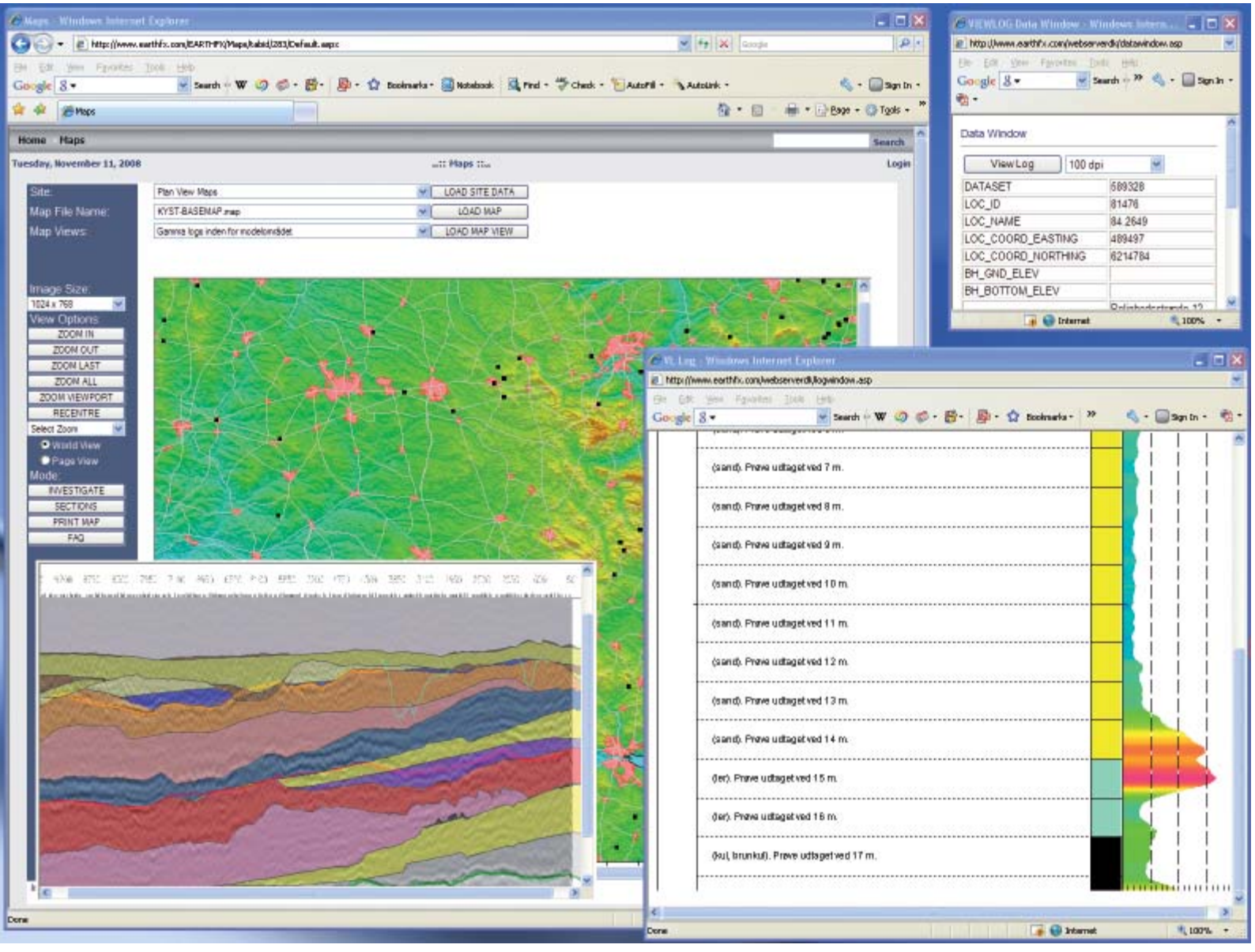

Når et projekt er sat op på webserveren, gives der adgang til at inspicere projektet over internettet. Det er $f x$ muligt at undersøge den rummelige model ved at lave tvcersnit eller udforske lithologien og geofysiske logs $i$ boringer. Det mioccene projekt kan frit inspiceres på http://www. earthfx.com/EARTHFX/denmark/. (Grafik: Forfatteren) 